\title{
PNL (Perkütan Nefrolitotomi) Ameliyatlarında Kullanılacak Artırılmış Gerçeklik Simülasyonu
}

\author{
Hüseyin $\operatorname{Yaman}^{1 *}$, Levent Civcik $^{2}$ \\ ${ }^{1}$ Selçuk Üniversitesi, Teknoloji Fakültesi, Bilgisayar Mühendisliği Bölümü, Konya, Türkiye (ORCID: 0000-0003-4933-5963) \\ ${ }^{2}$ Konya Teknik Üniversitesi, Teknik Bilimler Meslek Yüksek Okulu, Bilgisayar Teknolojileri Bölümü, Konya, Türkiye (ORCID: 0000-0002-4580-8164)
}

( $1^{\text {st }}$ International Conference on Computer, Electrical and Electronic Sciences ICCEES 2020 - 8-10 Ekim 2020)

(DOI: 10.31590/ejosat.804466)

\begin{abstract}
ATIF/REFERENCE: Yaman, H. \& Civcik, L. (2020). PNL (Perkütan Nefrolitotomi) Ameliyatlarında Kullanılacak Artırılmış Gerçeklik Simülasyonu. Avrupa Bilim ve Teknoloji Dergisi, (Özel Sayı), 293-296.

$\ddot{\mathbf{O} z}$

Perkütan nefrolitotomi (PNL), $2 \mathrm{~cm}$ üzerindeki böbrek taşlarında ve karmaşık böbrek taşları için önerilen minimal invaziv tedavi yöntemidir. Oldukça hassas olan operasyonlarda başarısızlıkla sonuçlanabilecek komplikasyonlar gelişebilir. Bu sebeplerden dolayı, bu çeşit cerrahi operasyonlarda personel eğitimi oldukça kritiktir. Bu tür cerrahi operasyonlar hakkında teorik bilgi edinmek, başarılı bir operasyon süreci için yetersizdir. Bu sebeple yapılan kadavra ve hayvan modelleriyle eğitimin maliyeti yüksek ve sinırlıdır. Bu çalışmada günümüzde birçok alanda kullanım yeri bulan artırılmış gerçeklik (AR) teknolojisinin, PNL'de başarıyı artırmak için cerrahi personelin yeni nesil eğitim sistemlerinde kullanımının uygunluğu ortaya konmuştur.
\end{abstract}

Anahtar Kelimeler: Artırılmış Gerçeklik (AR), Perkütan nefrolitotomi (PNL), Böbrek, Tedavi, Eğitim

\section{Augmenting Reality Simulation to be Used in PNL (Perkütan Nefrolitotomi) Surgeries}

\begin{abstract}
Percutaneous nephrolithotomy (PNL) is a minimally invasive treatment method recommended for kidney stones larger than $2 \mathrm{~cm}$ and complex kidney stones. Complications that may result in failure may develop in highly sensitive operations. For these reasons, staff training is critical in these types of surgical operations. Learning theoretical knowledge about these types of surgical operations is insufficient for a successful operation process. For this reason, the cost of training is high and limited with cadaver and animal models. In this study, the appropriateness of the use of augmented reality (AR) technology, which has been used in many areas today, in new generation training systems of surgical personnel to increase the success in PNL has been revealed.
\end{abstract}

Keywords: Augmented Reality (AR), Percutaneous Nephrolithotomy (PNL), Kidney, Treatment, Education.

\section{Giriş}

Usta-çırak ilişkisine dayanan cerrahi eğitim sürecinde, günümüzde mesai saatlerindeki kısıtlılık (Howells vd.,2008:90:494-9) hasta güvenliği (Cannon vd., 2006:442:21-9) ve cerrahi vaka oranında azalma sebebi ile aksaklıklar oluşmaktadır. Bu nedenle farklı eğitim yöntemlerine ihtiyaç duyulmaktadır. Kadavra, hayvan ve anatomik model kurslar bu ihtiyaçlara yönelik eğitim yöntemleridir. Fakat bu yöntemler maliyetli olmakla birlikte sınırlı deneyim sunmaktadırlar (Gomoll vd.,2007:35:883-8)-(Modi vd., 2010;26:832-40). Bu sebeple teknolojinin sağladığı imkanlar sayesinde artırılmış gerçeklik bilgisayar simülasyonları oldukça ön plana çıkmaktadır (Michelsen ,2006:88)-(Rosenberg vd.,2005:19:372-6)-(Gomoll vd., 2008:36:1139-42)- (Phillips vd.,2017:45:2125-2130) (Martin vd., 2016:474:965-70).

\footnotetext{
* Hüseyin Yaman Selçuk Üniversitesi, Teknoloji Fakültesi, Bilgisayar Mühendisliği Bölümü, Konya, Türkiye (ORCID: 0000-0003-4933-5963) huseyinyamanbilsem@gmail.com
} 
Havacıllk sektöründeki pilot eğitimlerinde uzun süredir kullanılmakta olan Artırılmış Gerçeklik Bilgisayar Simülasyonları (Pedowitz vd., 2002:18:1-6) son yıllarda da gelişen teknoloji ile birlikte ameliyathane performansı öncesi temel becerileri ve deneyim kazandırmak için kullanılmaya başlanmıştır (Gomoll vd.,2007:35:883-8), (Modi vd.,2010:26:832-40), (Henn vd.,2013:29:982-5).

Bu çalışmada, yenilikçi öğretim metotlarından olan sanal gerçeklik (VR) artırılmış gerçeklik (AR) teknolojisi ile PNL ameliyatları eğitiminde kullanılabilecek "Artırılmış Gerçeklik Simülasyonu" hakkında bilgi paylaşımı amaçlanmıştır. Elektronik ortamda gerçekleştirilecek PNL beceri uygulaması öğrencinin, hayati önem taşıyan bir aktivitede, gerçek ortamdaymış gibi hissederek risk almadan yapay veya sanal deneyim kazanacağı ve teknolojiyi kullanma becerisini geliştireceği bir öğrenme ortamı yaşamasını sağlayacaktır.

\section{Perkütan Nefrolitotomi (Pnl)}

Türkiye'de endemik olarak kabul edilen üriner sistem taşları bilinen en eski hastalıklardan biridir (Gomoll vd.,2007:35:883-8). Böbrek taşı hastalığı farklı coğrafyalarda, Kuzey Amerika'da \%7-13, Avrupa'da \%5-9 ve Asya'da \%1-5 gibi, farklı oranlarda ortaya çıan bir hastalıktır (Sorokin vd., 2017:35). Türkiye'de taş hastalığı insidansı \%14,8'dir. Üriner sistem taş hastalığı Türkiye de 45 ila 54 yaşları arasında en sik görülmektedir. Güneydoğu Anadolu en yüksek prevalansa sahip bölgesidir (Turgut vd.,2014;9:31-37).

Böbrek toplayıcı sistemine perkütan girişi ilk kez 1950'lerde tarif edildi. 1970'lerde böbrek taşı için minimal invaziv tedavi seçeneği olarak perkütan nefrolitotomi (PNL) kullanılmaya başlanmış ve daha sonraki yıllarda daha da gelişmiştir (Alken vd., 1982;8:304-11). Anestezi yöntemlerinde ve teknolojideki gelişmelere bağlı olarak taş hastalığının cerrahi tedavisi önemli ölçüde değiş̧iklik göstermiştir. 1976 yılında ilk kez Fernström ve Johannson tarafindan tanımlanan perkütan nefrolitotomi (PNL) bu değişikliklerden en önemlisidir (Tefekli ve Cezayirli, 2013:423964).

Litotripsi teknolojisindeki gelişme ve ayrıca aletlerin geliştirilmesi (esnek nefroskoplar gibi) ve (holmium/itriyumalüminyum-garnet lazer), perkütan nefrolitotomide taş parçalanmasının etkinliğini arttırarak, taşsızlık oranın $>\% 90$ olmasını sağlamıştır (Taylor vd.,2012;1:223-8). PNL 2 cm'den daha büyük böbrek taşlarında altın standart cerrahi tedavi yöntemi olmakla birlikte \%20'den \%83'e varan komplikasyon oranları bildirilmektedir (Türk vd., 2015;69:468)-(Taylor vd., 2012;1(4):223-8).

\section{Böbrek Anatomisi}

Böbrekler T12-L3 omurgaları arasında karın boşluğunun arkasında yer alırlar. Arkada Psoas Major kası üzerinde ve kasın dik aksına paralel, hafif oblik olarak yer alırlar. Üst kutbu alt kutbuna göre daha orta hatta yakın ve daha arkada yerleşimlidir. Böbreğin hiler bölgesinin öne doğru dönüklüğü sebebiyle her iki böbreğinde yan kenarları arkada yerleşimlidir. Bu dönüşs sonucu böbreğin ön ekseni ile vücudun ön keseni 30-50 derecelik açı yapar (Coleman 1987:13-32).

Sol böbrek ortalama $11,2 \mathrm{~cm}$, sağ böbrek ortalama $10,9 \mathrm{~cm}$ dir. Her iki böbreğin üst kutbu (üst bölgesi) alt kutbuna göre daha geniştir. Perkütan girişimlerde böbrekte olabilecek hasarları en aza indirebilmek için böbreklerin ve komşuluklarının üç boyutlu formuna tam olarak hâkim olmak gerekir (Sampaio ve Lacerda, 1989:95:77-80).

Sağ böbrek üstte böbrek üstü bezi, önde kc ve hilus yakınlarında 12 parmak bağırsağı, ana toplar damar, altta karın boşluğu arkasında olan kalın bağırsağın karaciğer tarafındaki dönüş bölgesi ile komşudur. Sol böbrek üstte böbrek üstü bezi, üst dışta dalak, hilus dolaylarında pankrasın kuyruk bölgesi, ön üstte mide, altta ince bağırsak bölümleri (orta bağırsak ve son bağırsak) ve kalın bağırsakla komşudur. Her iki böbrek arkada diyafram, kuadratum lumborum kası ve psoas kası ile bitişiktir. Böbreğin kalın bağırsak ile komşuluğu çok önemlidir. Böbrek arkasında yerleşmiş kalın bağırsak varlığında kalın bağırsak böbrek alt polü ile komşuluk gösterir. BT ile yapılan çalı̧̧malarda sırtüstü yatar pozisyonda \%1,9 olguda böbrek arkasında yerleşimli kalın bağırsak tespit edilirken bu olgular PNL'de uygulanan yüzükoyun pozisyonunda alındığında \%10 olguda böbrek arkasında yerleşimli kalın bağırsak tespit edilmiştir (Caner 2016).

\section{Hasta Pozisyonu}

PNL'de genelde hasta pozisyonu prone (yüzükoyun) pozisyondur. Prone pozisyonu böbreğe girişte ve böbreğe girdikten sonra operasyon sürecinde geniş bir müdahale alanı sağlayarak avantaj sağlamaktadır. İç organ hasarı bu pozisyon da azalmaktadır. Buna rağmen Prone pozisyonunun dezavantajları olarak solunum ve dolaşım sıkıntıları olası göz, spinal ve periferal sinir sorunlarını sayabiliriz. Obez, solunum ve dolaşım sıkıntıları olan hastalarda bu sorunlar daha ön plana çıkmaktadır. Bu nedenle farklı pozisyon arayışları başlamış ve supin pozisyon gündeme gelmiştir (Özlülerden ve Tuncay 2020;12(1);35-44).

Günümüzde büyük ve kompleks böbrek taşlarının tedavisinde önerilen modalite olan PNL, yıllar içerisinde hem taşsızlık oranlarını arttırmak hem de komplikasyonları en aza indirmek için çeşitli modifikasyonlara uğramıştır. Lazer teknolojisinin gelişimi ile PNL, retrograd intrarenal cerrahi (RIRS) ile rekabetinde minyatürize olarak kendisine yeni yaşam sahaları oluşturdu. Bir önemli değişim de diğer birçok başka avantajı ile birlikte ergonomik bir biçimde endoskopik kombine intrarenal cerrahi (ECIRS) yapılabilmesine de olanak sağlaması açısından supin pozisyona geçiş oldu (Ibarluzea vd., 2007;100:233-6).

\section{Dilatasyon}

PNL operasyonu esnasında seçilecek dilatasyon tekniği, muhtemel komplikasyonlar bakımından oldukça önemlidir. Nefrostomi traktının akut dilatasyonu birçok enstrumanla yapılabilir. En çok kullanılan; seri olarak uygulanan ve gittikçe kalınlaşan fasyal 
dilatatörler, amplatz dilatasyon seti, metal yardımcı dilatatörler ve yüksek basınçlı balonlardır. Cerrahi personelin deneyimi ve tercihleri ile ilişkili olarak tüm dilatasyon teknikleri güvenle kullanılabilir (Turgut vd., 2014:31-37).

PNL esnasında böbrek damarlarının yaralanmasına bağlı olarak kanama görülür. Çoğunlukla iğnenin girişi, traktın dilatasyonu esnasında, nefroskopi yapılırken veya postoperatif dönemde ciddi kanamalar görülür. PNL minimal bir yaklaşım işlemidir. Bu yaklaşım sırasında kanamalar pek çok sefer kontrol edilememektedir. En ideal şekilde böbreklere yapılan giriş PNL den kaynaklanan kanamaları önemli derecede engellemektedir. Böbrek taşın merkezine uygulanan ilk iğne girişi minimum mesafe en doğru açıda olmalıdır. Genişlemede kullanılan metot iğne giriş işleminden sonra kanama oranlarını değiştirmektedir.

\section{Tartışma- Dilatasyon İşıleminde Artırılmış Gerçeklik Kullanımı:}

Bir konu hakkında bilgi edinmek, davranış değişikliği kazandırmaya yetmeyebilir. Özellikle de acil durumlarda davranışa dönüşmesi istenen bilginin, öğrenen tarafından algılanması, deneyimle pekiştirilmesi ve uzun süreli belleğe kaydedilmesi gerekmektedir. Bilginin kalıcılığıyla ilgili eğitim ve öğrenimde devrim niteliğinde yeni firsatlar sunan AG uygulamaları, eğitilenin personelin tecrübe kazanmasında büyük rol oynamaktadır. AG ile verilen eğitimler planlı biçimde verilmesi sebebi ile bilginin eğitilen personele aşamalı olarak verilmesi sağlamaktadır. Gerçek olayların rastlantısal sonuçları yerine bilinçli olarak alternatif durumların her birisi ele alınabilmektedir. Tekrar eden deneyim ortamı sayesinde bilginin işlenip kalıı bir anı niteliği kazanması sağlanır. Eğitilen personelin istendik davranışı tekrar tekrar uygulama yaparak pekiştirmesi gibi özellikler ile etkili bir öğrenme sağlanabilmektedir. Bu nedenlerle AG uygulamaları ile verilen eğitim sayesinde (Telli vd., 2018), birçok zor alanda başarılı olan artırılmış gerçeklik yöntemi cerrahi uzmanlık ve beceri isteyen dilatasyon yöntemi içinde faydalı olacağı öngörülmektedir.

Böbrek anatomisinin iyi bilinerek komşu olduğu hassas bölgelere zarar vermeden Perkütan Nefrolitotomi ameliyatlarında kesi noktasının tespit edilmesi önem teşkil etmektedir. Ayrıca Artırılmış Gerçeklik sayesinde bilgilerin hızlı ve kolaylıkla aktarımı gerçekleşmektedir. Endüstriyel ve çevresel tehlikelerden izole edilmesi sebebiyle cerrahi yöntemleri hijyenik ortamlar gerektirmesi nedeniyle Artırılmış Gerçeklik oldukça güvenlidir. Laboratuvar ve kadavra gerektirmediğinden uygulamada tasarruf sağlamaktadır. Zamandan ve mekândan bağımsız eğitsel deneyim imkânı tanımaktadır. Sınırsız tekrarlanabilir olması sebebi ile eğitilen personelin tecrübesi artmaktadır. Eğitilen personele 3 boyutun sürükleyici bir deneyim sunması nedeniyle PNL ameliyatlarında kullanılan dilatasyon yönteminin ve hassas kesi noktasının daha iyi belirlenmesine olanak vermektedir. Bu nedenle Artırılmış Gerçeklik birçok cerrahi yöntemlerin uygulanmasında olduğu gibi PNL yönteminde de yaşanan sıkıntıları sanal olarak simüle edilerek, eğitim alan personelin rahat bir ortamda deneyim kazanması sağlanır. Bireysel adımların tekrarlanabilir olması nedeniyle eğitilen personele farklı bakış açılarından ve görüşlerden PNL sürecini analiz etme firsatı sağlaması nedeniyle Artırılmış Gerçeklik yöntemlerinin uygulanması önemlidir (Macchiarella vd., 2005)-(Erkoyuncu vd., 2016 :64-69).

\section{Yöntem}

PNL ameliyatlarından önce Bilgisayarlı Tomografi işlemi sırasında elde edilen veriler üç boyutlu olarak sanal gerçeklik ortamına aktarılır. Yapay zekâ kullanılarak en doğru biçimde hesaplamalar yapılır ve cerrahi personel sanal gerçeklik ortamında bilgilendirilir. PNL ameliyatlarında kullanılan dilatasyon yönteminin ve hassas kesi noktasının en doğru biçimde Artırılmış Gerçeklik vasıtasıyla cerrahi personel ameliyat öncesi deneyim kazanması sağlanır.

\section{Dezavantajlar}

Tüm bu olumlu yönlerinin yanı sıra Artırılmış Gerçeklik AG önünde teknolojik engellerin (altyapı, çözünürlük, fiziksel etkileşim zorlukları vb.) bulunması, aşırı bilişsel yüke neden olması, donanım ile yazılımların yüksek maliyetli olması, içerik geliştirme zorluğu, teknik bilgi yetersizlikleri, geliştirme ve bakım masrafları gibi dezavantajları bulunmaktadır. Bu alanda karşılaşılan en büyük zorluk ise uygun içeriğin ve uygun görüntüleme teknolojisinin geliştirilmesidir. AG uygulamaları kapsamındaki dezavantajların teknolojinin ilerlemesi ve zaman içinde olumlu sonuçların alınması ile birlikte ortadan kalkacağı değerlendirilmektedir.

\section{Kaynakça}

Howells N, Gill H, Carr A, Price A, Rees J. Transferring simulated arthroscopic skills to the operating theatre. J Bone Joint Surg Br. 2008; 90: 494-9),

Cannon WD, Eckhoff DG, Garrett Jr WE, Hunter RE, Sweeney HJ. Report of a group developing a virtual reality simulator for arthroscopic surgery of the knee joint. Clin Orthop Relat Res. 2006; 442: 21-9.)

Gomoll AH, O'toole RV, Czarnecki J, Warner JJ. Surgical experience correlates with performance on a virtual reality simulator for shoulder arthroscopy. Am J Sports Med. 2007; 35: 883-8.

Modi CS, Morris G, Mukherjee R. Computer-simulation training for knee and shoulder arthroscopic surgery. Arthroscopy. 2010; 26: $832-40$.

Michelson JD. Simulation in orthopaedic education: an overview of theory and practice. J Bone Joint Surg Am. 2006; 88: 1405-11.

Rosenberg BH, Landsittel D, Averch TD. Can video games be used to predict or improve laparoscopic skills? J Endourol. 2005; 19: 372-6.

Gomoll AH, Pappas G, Forsythe B, Warner JJ. Individual skill progression on a virtual reality simulator for shoulder arthroscopy a 3year follow-up study. Am J Sports Med. 2008; 36: 1139-42. 
Phillips L, Cheung JJ, Whelan DB, Murnaghan ML, Chahal J, Theodoropoulos J, et al. Validation of a Dry Model for Assessing the Performance of Arthroscopic Hip Labral Repair. Am J Sports Med. 2017; 45: 2125-2130.

Martin RK, Gillis D, Leiter J, Shantz JS, MacDonald P. A porcine knee model is valid for use in the evaluation of arthroscopic skills: a pilot study. Clin Orthop Relat Res. 2016; 474: 965-70

Pedowitz RA, Esch J, Snyder S. Evaluation of a virtual reality simulator for arthroscopy skills development. Arthroscopy. 2002; 18: 16.

Gomoll AH, O'toole RV, Czarnecki J, Warner JJ. Surgical experience correlates with performance on a virtual reality simulator for shoulder arthroscopy. Am J Sports Med. 2007; 35: 883-8.

Modi CS, Morris G, Mukherjee R. Computer-simulation training for knee and shoulder arthroscopic surgery. Arthroscopy. 2010; 26: 832-40.

Henn RF, Shah N, Warner JJ, Gomoll AH. Shoulder arthroscopy simulator training improves shoulder arthroscopy performance in a cadaveric model. Arthroscopy. 2013; 29: 982-5.

Sorokin I, Mamoulakis C, Miyazawa K, et al. Epidemiology of stone disease across the World. World J Urol. 2017;35(9):1301-20. https://doi.org/10.1007/s00345-017-2008-6.

Hasan Turgut1, Akif Diri2, Murat Bağcığlu3, Tolga Karakan4, Cankon Germiyanoğlu5 Perkütan nefrolitotomi operasyonlarında kullanılan balon ve amplatz dilatasyon tekniklerinin karşılaştırılması Yeni Üroloji Dergisi - The New Journal of Urology 2014; 9 (3): $31-37$

Alken P, Hutschenreiter G, Guenther R. Percutaneous kidney stone removal. EurUrol. 1982; 8:304-11. https://doi.org/10.1159/000473540

Tefekli A, Cezayirli F. The history of urinary stones: in parallel with civilization. Scientific World J 2013;423964. https://doi.org/10.1155/2013/423964

Taylor E, Miller J, Chi T, et al. Complications associated with percutaneous nephrolithotomy. Transl Androl Urol. 2012;1(4):223-8. https://doi.org/10.3978/j.issn.2223-4683.2012.12.01

Türk C, Knoll T, Petrik A et al. European association of urology, guidelines on urolithiasis. Eur Urol. 2015;69:468. https://doi.org/10.1016/j.eururo.2015.04.021

Taylor E, Miller J, Chi T, et al. Complications associated with percutaneous nephrolithotomy. Transl Androl Urol. 2012;1(4):223-8. https://doi.org/10.3978/j.issn.2223- 4683.2012.12.01

Coleman CC. Percutaneous nephrostomy: Renal anatomy. In Amplatz K, Lange PH, eds. Atlas of endourology. Chiago: Year book, 1987, pp13-32.

Sampaio FJB, Lacerda CAM. Morphometrie du rein. Etude appliquee a I'urologie et a I'imagerie. J Urol (Paris) 95:77-80, 1989.

Perkütan Nefrolit Operasyonu Sonrası Kanamaya Etki Eden Faktörler Uzmanlık Tezi Dr. Mehmet Caner Gülten Tez Danışmanı Prof. Dr. Ömer Levent Tuncay Denizli-2016

Yusuf Özlülerden, Ömer Levent Tuncay, Prone Percutaneous Nephrolitotomy Endourol Bull 2020;12(1);35-44 e-ISSN:2148-0532

Ibarluzea G, Scoffone CM, Cracco CM, Poggio M, Porpiglia F, Terrone C, et al. Supine Valdivia and modified lithotomy position for simultaneous anterograde and retrograde endourological access. BJU Int 2007;100:233-6.).

Hasan Turgut1, Akif Diri2, Murat Bağcığlu3 , Tolga Karakan4, Cankon Germiyanoğlu5 Yeni Üroloji Dergisi - The New Journal of Urology 2014; 9 (3): 31-37

G. Telli Yamamoto, N. Zümrüt, D. Altun, “İş Kazalarının Önlenmesinde Sanal Gerçeklik Teknolojisi İle Deneyimsel Öğrenme,” Maltepe Üniversitesi Uluslararası İşletme ve Pazarlama Kongresi, İstanbul 2018

N.D. Macchiarella, D. Liu, S.N. Gangadharan, "Augmented Reality as a Training Medium for Aviation/Aerospace Application," Proceedings of the Human Factors and Ergonomics Society Annual Meeting, 2005

J.A. Erkoyuncu, M. Alrashed, M.M. Dalle, R. Michela, D.G. Rajkumar, "Real life augmented reality for maintenance," Int'l Conf. Modeling, Sim. and Vis. Methods (MSV'16), 64-69, 2016 